International Journal of Microwave Engineering (JMICRO) Vol.1, No.1, January 2016

\title{
Novel Approach Of Microstriptri-Band Bandpass Filter for GSM, Wimax And UWB Application
}

\author{
Tasher Ali Sheikh, Janmoni Borah\& Sahadev Roy \\ Dept. of Electronics and Communication Engineering \\ National Institute of Technology, \\ Yupia, Arunachal Pradesh-791112, India
}

\begin{abstract}
In this paper, a novel approach of miniature tri-band microstrip bandpass filter is design for the application of $\operatorname{GSM}(1.8 \mathrm{GHz})$,WiMAX $(3.4 \mathrm{GHz})$ and $U W B(6.5-8.1 \mathrm{GHz})$ using Asymmetric SIRs and DGS to achieved the basic characteristic of microstrip filter such as low insertion loss, high selectivity, wider range of bandwidth, low group delay. The novel filter is design intentionally selecting the impedance ration $(R)$ and length of the microstrip of the asymmetric SIRs and DGS is used to improve the coupling strength of the desired band. The measurement entities of the novel filter for GSM $(1.8 \mathrm{GHz})$, WiMAX $(3.4 \mathrm{GHz})$, and $U W B(6.5-8.1 \mathrm{GHz})$ are insertion losses $\left(S_{21}\right)$ are $-0.07 \mathrm{~dB} /-0.21 \mathrm{~dB} /-0.12 \mathrm{~dB}$, and return losses $\left(S_{11}\right)$ are $-31 \mathrm{~dB} / 15 \mathrm{~dB} / 30 \mathrm{~dB}$ respectively. The response of the filter was simulated using An soft HFSS Simulator.
\end{abstract}

Keywords

BPF, WiMAX, UWB, Asymmetric SIRs, DGS, FBW.

\section{INTRODUCTION}

Miniature and selective required resonance frequency pass bands from the wider range of frequencies are the major attraction in the wireless communication systems [1].To constitute the multi-band in a single system in the electronic devices and filter unwanted frequencies abstract is more interest in Morden microwave filter design Techniques [2-3].Therefore multi-band filter obtain a great interest from last few decades in modern wireless communication system. Microstrip multi-band filter can easily fabricate and integrated on dielectric substrate and providing high design freedom during exact measurement of width, length and thickness of the microstrip lines[4]. The multi-band Bandpass filter is design in many authors, but still it is large circuit area and high design complexity which are not fruitful for wireless communication systems where miniaturization is most vital issue now-a-days in the miniaturize Bandpass filter design methods [5].In RF and microwave communication devices, in wireless communication systems multiple service Bandpass filtersare carryout more and more interest and aggressively developed and design.In radio frequency front end, Bandpass filter plays a key role for selecting the desired band and attenuated the unwanted band from the signals. A tri-band microstrip BPF was proposed to realize with compact size, low return loss and wide band characteristics that is discuss details in [6].

In microstrip filter design, Stepped impedance resonators is widely used to design Bandpass filter because of compact in size, low insertion loss, proper coupling flexibility, high design freedom of selecting the electric length ratio $(\mu)$ and impedance ratio $(R)$ in the desired filter to achieved the desired band [8-9].A new methods of design to improve the response in Bandpass filter and 
increases the bandwidth allocation in the passband response, defected SIRs, using the DGS [10].Stepped impedance resonators are also used to acquire UWB response by controlling the resonance frequencies in closed and configuring the strong coupling on side the resonators [11].UWB filter were design using the SIRs and a DGS by combining of wide band and rejected notch-band [12-14].

In this paper, novel ways of designing the tri-band microstrip bandpass filter using one pair of Asymmetric SIRs and DGS. We obtain three centre frequency band $1.8 \mathrm{GHz}, 3.4 \mathrm{GHz}$ and6.5$8.10 \mathrm{GHz}$ by intelligently selecting the impedance ratio(R) and electrical length ratio $(\mu)$ of the proposed filter SIRs and DGS. Obtained the tri-band response by integrated the two narrow passband with wideband response [15].

\section{DESIGN METHODOLOGY}

The coupling scheme is shown in fig. 1 of the proposed Bandpass filter. The proposed filter layout is shown in the Fig. 2. Basically the BPF consisting one pair of Asymmetric SIRs and a DGS on ground plane and couple of Input/output microstrips line. Firstly two narrow passband are design using two Asymmetric SIRs to obtain the centre frequency $1.8 \mathrm{GHz}$ and $3.4 \mathrm{GHz}$ for the application of GSM $(1.8 \mathrm{GHz})$, WiMAX $(3.4 \mathrm{GHz})$ and UWB $(6.5-8.1 \mathrm{GHz})$. The last passband is design by using the defected ground structure on the ground plane with microstrip line to get the ultra-wideband frequency response. The DGS is arrange under the ground plane of the symmetrically to avoid the design complexity and reduces the compensation. If the electrical length ratio and impedance ratio are different the DGS will be affected the other resonator modes of asymmetric SIRs. Finally by integrated the tri-bands response is obtained that is reported in the observation part. The passband are obtain form the resonator 1 and resonator 2 and the second passband are form the resonators 3 and resonators 4.The last band are measure form the resonators $1,3,4$ and 2 .

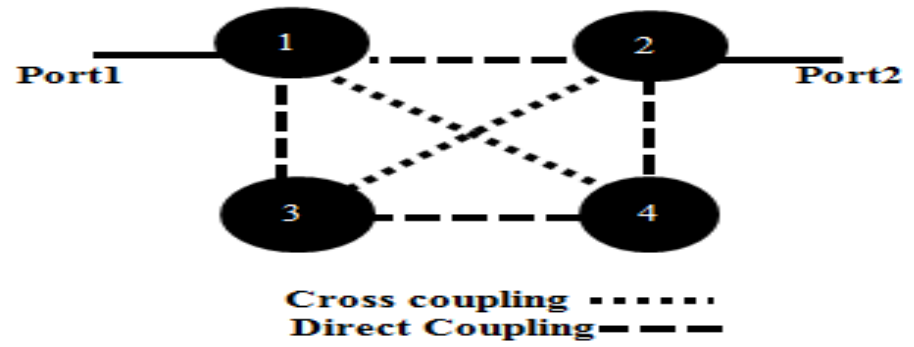

Fig1. Coupling Scheme Of The Proposed Filter.

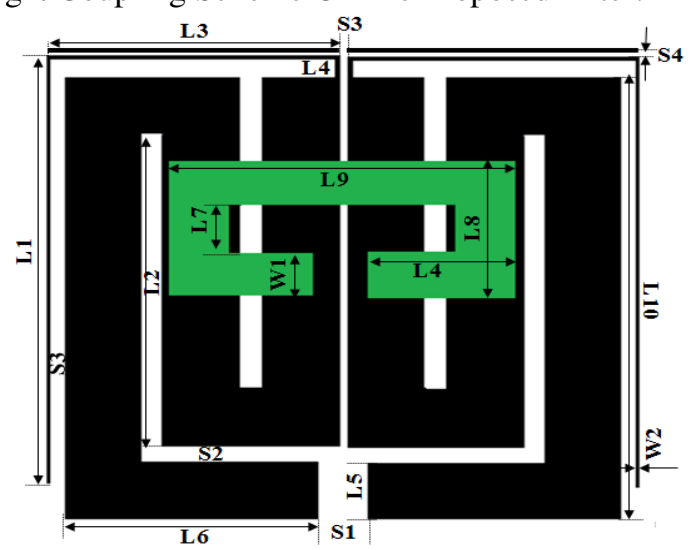

Fig2.The Proposed Filter Layout. 
It was known that DGS under the coupling resonators can be seen as a parallel LC resonator [20]; the capacitance and the inductance are calculate using (1) and (2)

$$
\begin{aligned}
& C=\frac{\omega_{c}}{Z_{0} g} \cdot \frac{1}{\omega_{0}^{2}-\omega_{c}^{2}} \\
& L=\frac{1}{4 \pi^{2} f_{0}^{2} C}
\end{aligned}
$$

Where $\omega_{c}, \omega_{o}$ is the cut-off frequency and Centre frequency of the low-pass filter, $\mathrm{Z}_{0}$ the Characteristic impedance of the input/output ports, and ' $\mathrm{g}$ ' given by the element value of the prototype Low Pass Filter. The operating frequency of DGS can be lowered while the reactance is increased by generally increasing the area or the number of DGSs. The centre frequency and the relative fractional bandwidth (FBW) can be measure by the following equation

$$
\begin{aligned}
\omega_{0}=\sqrt{\omega_{1} \omega_{2}} \\
F B W=\frac{\omega_{2}-\omega_{1}}{\omega_{0}}
\end{aligned}
$$

\section{SIMULATION RESULT DISCUSSIONS}

Based on design structure as shown in the fig. 2 the response of the proposed filter and their Sparameters is depicted in fig. 3. The magnitude of $S_{11}$ and $S_{21}$ vs. frequency plot at the centre frequency 1.8/3.4/6.5-8.1 (GHz) responses and the phase difference of transmission are shown in fig.3. The insertion losses $\left(\mathrm{S}_{21}\right)$ are very low those are $-0.07 \mathrm{~dB} /-0.21 \mathrm{~dB} /-0.12 \mathrm{~dB}$ and the return losses $\left(\mathrm{S}_{11}\right)$ are $--31 \mathrm{~dB} /-15 \mathrm{~dB} /-30 \mathrm{~dB}$ for the GSM $(1.8 \mathrm{GHz})$, WiMAX $(3.4 \mathrm{GHz})$ and UWB $(6.5-$ $8.1 \mathrm{GHz})$ respectively. The appearing of transmission zeros at the end of the each side of the passband improved the selectivity that is shown in the fig. 3 and Fig.5 and it are granted the sharpness of the scattering parameters of the design filter response. The minimum transmission zero is $-77 \mathrm{~dB}$ at the frequency $(1.15 \mathrm{GHz})$ and the maximum is $-50 \mathrm{~dB}(8.23 \mathrm{GHz})$. The appearance of two transmission poles at each passband at the last two band increases the $3 \mathrm{~dB}$ bandwidth as shown in Fig. 3 and Fig. 4. The group delay is calculating by taking the derivative of phase, which is inversely proportional to bandwidth as shown in Fig.6.The Group delay for GSM $(1.8 \mathrm{GHz})$, WiMAX $(3.4 \mathrm{GHz})$ and UWB that are $5 \mathrm{~ns}$ at $1.8 \mathrm{GHz}$ and $0.12 \mathrm{~ns}$ at $3.4 \mathrm{GHz}$ and $2.5 \mathrm{~ns}$ at $(6.5-8.10 \mathrm{GHz})$ which are shown in the fig. 6. In this design, the group delay for GSM $(1.8 \mathrm{GHz})$, WiMAX $(3.4 \mathrm{GHz})$ and UWB are good and applicable.

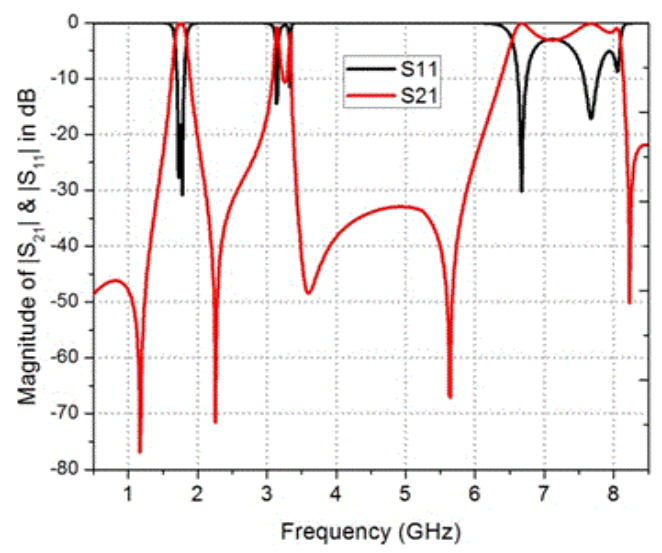

Fig3. $S_{21}$ and $S_{11}$ vs. Frequency Plot. 
International Journal of Microwave Engineering (JMICRO) Vol.1, No.1, January 2016

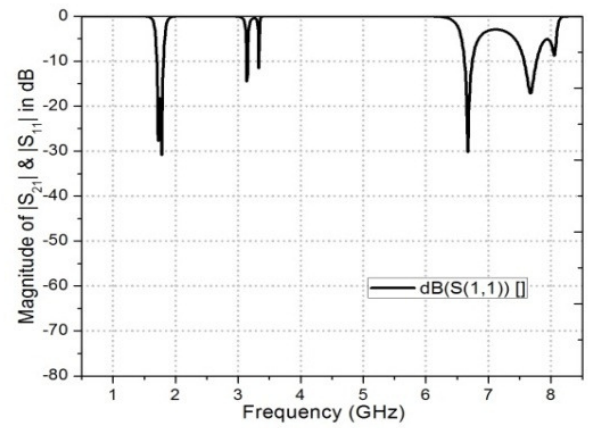

Fig4. $\mathrm{S}_{11}$ Vs. Frequency Plot.

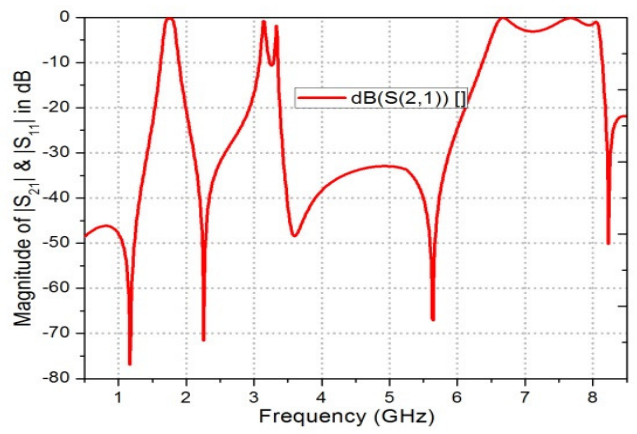

Fig5. $\mathrm{S}_{21}$ Vs. Frequency Plot.

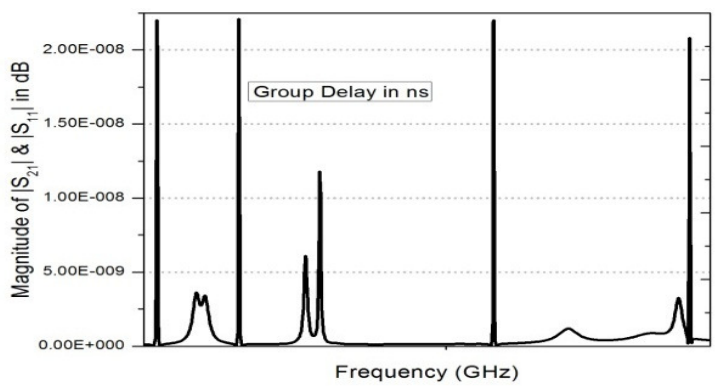

Fig6.GroupDelay (Ns) Vs. Frequency Plot

The Fractional Bandwidth (FBW) Of The Proposed Filter Is Measure Using Ansoft HFSS Simulator. The FBW Is 9.77\%/2.22\%/22.03 With Centre Frequency 1.8ghz, 3.4ghz And UWB (6.5-8.10GHZ) Respectively. 


\section{DIMENSION CALCULATION AND COMPARISON OF RESULT}

The proposed filter was simulated using the Ansoft HFSS Simulator design on a Rogers RT/ Duriod 5880 substrate with thickness of $0.787 \mathrm{~mm}$, dielectric constant $\left(\varepsilon_{\mathrm{r}}\right)$ of 2.2 and tangent loss ( $\delta) 0.0009$. The filter achieves a high impedance $(Z 1=66.2 \Omega)$ with strip width $0.2 \mathrm{~mm}$ and low impedance is $(\mathrm{Z} 2=47.17 \Omega)$ with strip width $3.85 \mathrm{~mm}$. The dimension of the proposed filter are $\mathrm{L} 1=14.65 \mathrm{~mm}, \mathrm{~L} 2=10.55 \mathrm{~mm}, \mathrm{~L} 3=7.45 \mathrm{~mm}, \mathrm{~L} 4=3.7 \mathrm{~mm}, \mathrm{~L} 5=2 \mathrm{~mm}, \mathrm{~L} 6=6.5 \mathrm{~mm}, \mathrm{~L} 7=16 \mathrm{~mm}$, $\mathrm{L} 8=4.6 \mathrm{~mm}, \mathrm{~L} 9=8.8 \mathrm{~mm}, \mathrm{~L} 10=15.05 \mathrm{~mm} ; \quad \mathrm{S} 1=1.2 \mathrm{~mm}, \quad \mathrm{~S} 2=0.2 \mathrm{~mm}, \quad \mathrm{~S} 3=0.5 \mathrm{~mm}, \quad \mathrm{~S} 4=0.1 \mathrm{~mm}$, $\mathrm{W} 1=1.5 \mathrm{~mm}, \mathrm{~W} 2=0.2 \mathrm{~mm}$, with microstrip width of $0.2 \mathrm{~mm}$. The complete in size of the proposed filter is $(17 \times 15) \mathrm{mm}^{2}$ which is very compact in size compared to other traditional design filters. It is reported that the proposed filter adequate very loss insertion loss, even when the strip width is high $(3.87 \mathrm{~mm})$. The performance improvement comparisons with previous work are reported in the table 1 .

Table 1. Comparison with Other Proposed Tri-Band Bpf

\begin{tabular}{|c|c|c|c|c|c|c|}
\hline $\begin{array}{l}\text { Comparison } \\
\text { of model }\end{array}$ & $\begin{array}{l}1^{\text {st }} / 2^{\text {nd }} / 3^{\text {rd }} \\
\text { Pass-band } \\
\text { (GHz) }\end{array}$ & $\left|S_{21}\right|$ in $\mathbf{~ d B}$ & $\mid S_{11} \operatorname{lin} \mathrm{dB}$ & FWB (\%) & $\begin{array}{l}\text { Dime } \\
\text { n-sion }\end{array}$ & $\begin{array}{l}\text { Applicatio } \\
\text { n }\end{array}$ \\
\hline Ref.[16] & $1 / 2.5 / 3.6$ & $2.2 / 1.8 / 1.7$ & $20 / 40 / 35$ & $5 / 2.1 / 1.4$ & $60 \times 60$ & $\begin{array}{l}\text { GSM } \\
\text { WiMAX } \\
\text { WLAN }\end{array}$ \\
\hline Ref.[17] & $1 / 2.5 / 3.6$ & $2.2 / 1.9 / 1.7$ & $15 / 35 / 20$ & $5 / 2.5 / 1.4$ & $40 \times 40$ & $\begin{array}{l}\text { GSM } \\
\text { WiMAX } \\
\text { WLAN }\end{array}$ \\
\hline Ref.[18] & 2.5/3.5/5.9 & $2.1 / 1.9 / 2.3$ & $18 / 30 / 22$ & $3.5 / 3.8 / 4.5$ & $60 \times 60$ & $\begin{array}{l}\text { WiMAX } \\
\text { WiMAX } \\
\text { WLAN }\end{array}$ \\
\hline Ref.[19] & $1.5 / 2.4 / 3.5$ & $1.6 / 1.5 / 2.3$ & 9/18/13.7 & $5.2 / 3.8 / 4.6$ & $\begin{array}{l}49 \times 56 . \\
2\end{array}$ & $\begin{array}{l}\text { GSM } \\
\text { WLAN } \\
\text { WiMAX }\end{array}$ \\
\hline Propose filter & $\begin{array}{l}1.8 / 3.4 / \\
6.5-8.1\end{array}$ & $\begin{array}{l}0.07 / 0.21 / 0.1 \\
2\end{array}$ & $31 / 15 / 30$ & $\begin{array}{l}9.77 / 2.22 / 22.0 \\
3\end{array}$ & $17 \times 15$ & $\begin{array}{l}\text { GSM } \\
\text { WiMAX } \\
\text { UWB }\end{array}$ \\
\hline
\end{tabular}

\section{CONCLUSION}

The new tri-band microstrip bandpass filter is proposed to achieved three passbands at the centre frequency 1.8/3.4/ (6.5-8.10) GHz for the application of GSM (1.8), WiMAX (3.4) and UWB (6.5-8.1) GHz.This filter has advantage that by controlling the resonators modes of the asymmetric SIRs of the proposed filter three bands can be tune. This is generally achieved by selecting the $\mathrm{R}$ and $\mu$ that is describe in introduction part. The filter configurations are with the asymmetric stepped impedance resonators and DGS in ground plane is arranging under the asymmetric SIRs and RT Duriod dielectric substrate. The propose multi-band bandpass filter of the last two passband produces the two transmission zeros at each, which evidence that selectivity of the filter is increases. From the table. 1 it is also evidence that circuit size of the propose filter 
greatly reduces about $70 \%$ than the other filter that are reported in this paper and $3 \mathrm{~dB}$ bandwidth is also increases compare to the other tri-band filters. The basic characteristic of the propose filter are insertion loss $\left(\mathrm{S}_{21}\right)$ are $-0.07 \mathrm{~dB} /-0.21 \mathrm{~dB} /-0.12 \mathrm{~dB}$ and the return losses $\left(\mathrm{S}_{11}\right)$ are $-31 \mathrm{~dB} /-15 \mathrm{~dB} /-$ $30 \mathrm{~dB}$ for the Centre frequency 1.8/3.4/6.5-8.10 (GHz) respectively. So from the above characteristic of the propose filter it is aspect that it is applicable in microwave integrated circuits, with high performance in the Radio frequency front-end, while wide range of attenuation bandwidth which makes it enables for the application of microwave communication, satellite and wireless communication systems and small cellular base station which are very demanding field in the communication systems.

\section{ACKNOWLEDGMENT}

Acknowledge the IC design and fabrication Centre Jadavpur University, Kolkata, India for extended their software facility and also thank NIT, Arunachal Pradesh for their valuable support to complete this research work.

\section{REFERENCES}

[1] Sheikh, T. A., Borah, J. and Roy, S., "Bandwidth Improvement in BPF Using Microstrip Couple Lines”, International Conference Signal and Speech Processing'14, Elsevier Publication, (2014), 105109.

[2] Sheikh, T. A., Borah, J. and Roy, S, Pandey, A. K. , "A New Compact Dual Band Microstrip BPF For GSM-1800 And WiMAX Using Asymmetric Stepped Impedance Resonators", ICRCWIP,SpringerConference Publication (ICRCWIP-15),Jan.2015.

[3] Sheikh, T. A., Borah, J. and Roy, S, "Miniaturized Tri-Band BPF using Asymmetric SIRs and DGS", International Journal of Signal processing, Image processing and pattern recognition (IJSIP)(2015),vol.8, no.2, 337-346.

[4] Lai, X.,Laing C.H,Di, H. and Wu B., "Design of tri-band filter based on stub loaded Resonator and DGS Resonator",IEEE Microw. And Wireless Compon. Letters, Vol.20.no.5 (2010), 265-267.

[5] Girdhari, C., and Kim, J., "Design of dual band bandpass filter using DGS with controllable second passband", IEEE Microw.Wireless Compon. Lett. Vol. 21, no.11, (2011), 589-591.

[6] Mohamed, H. A., Shaarawy, H. B.,Abdullah, E. A.,El-Hennawy, H. M., "A Very Compact novel Multi-Band BPF for Recent Mobile/Satellite Communication System", Progress in Electromagnetics research, Vol. 50, (2014), 47-56.

[7] Chen, W.Y., Weng, M.H., Chang, S. H. Kuan,H., and Su, Y.H., "A new Tri-band bandpass filter for GSM,WiMAX and Ultra-Wideband responses by using Asymmetric Stepped Impedance Resonators", Progress in Electromagnetic Research, Vol. 124, (2012), 365-381.

[8] Chen, X.P., Wu, K. and Li, Z.L., "Dual-band and triple-band substrate integrated waveguide filter with chebyshev and quasi-elliptic responses", IEEE Trans. Microw. Theory Tech., Vol. 55, (2007), 25692578.

[9] Chang, Y.C., Kao, C .H. Weng, M.H. and Yang, R.Y., "Design of the Compact Dual-Band Bandpass Filter With High Isolation for GPS/WLAN Applications", IEEE microwave and wireless component letters, Vol. 19,no.12 (2009), 780-782.

[10] Chu, Q.L. and Chen, F. C., "A Compact Dual-Band Bandpass Filter Using Meandering Stepped Impedance Resonators", IEEE Microwave and wireless Components Letters, Vol. 18,no.5, (2008), $320-632$.

[11] Li, R. and Zhu, L., "Compact UWB bandpass filter Using stub-loaded multiple-mode resonators", IEEE Microw. Wireless Compon. Lett. , Vol. 17, (2007), 40-42.

[12] Chen, W. F. L., Wu, Q.Y., Shi, X. W., and Gao, C. J., "Compact UWB bandpass filter with narrow notch-band and wide stop-band", Journal of Electromagnetic Waves and Applications, Vol. 24,no.7, (2010), 911-920. 
[13] Xu, J., Li, H Wang, H., Miao, C. and Wu, W., "Compact UWB bandpass filter with multiple ultranarrow notched bands", Journal of Electromagnetic Waves and Applications, Vol. 25,no.7, (2011), 987-998.

[14] Fallahzadeh, S., and Tayarani, M., "New microstrip UWB bandpass filter using defected microstrip structure", Journal of Electromagnetic Waves and Applications, Vol. 24,no.7, (2010), 893-902.

[15] Li, J., Huang, S. S., and Zhao, J. Z., "Design of a Compact and High Selectivity tri-band Bandpass filter Using Asymmetric SIRs", Progress in Electromagnetic Research Letters, Vol. 44, (2014), 81-86.

[16] Lin, M, and Chu, Q. X., "Design of triple-band bandpass filter using tri-section stepped impedance resonators", Proc. Int. Microw. Millimetre Wave Tech. Conf., (2007), 798-800.

[17] Chu, Q. X. and Lin, X. M., “Advance triple-band bandpass filter using tri-section SIR”, Electron. Lett. Vol.44, no.4, (2008), 295-296.

[18] Li, Z. N.Wang, S. J., Su, T. and Liang, C. H., "A novel triple passband filter method based on stepped impedance resonators", Progress in Electromagnetics Research C, Vol.33, (2012), 199-211.

[19] Yu, W., Weng, M. H. and Chang, S. J., "A new tri-band bandpass filter based on stub-loaded stepped impedance resonators", IEEE Microw. Wireless Compon. Lett. Vol.22, no.4 (2012), 179-181.

[20] Zhu, L., H. Bu, and K.Wu, “Aperture compensation technique for innovative design of ultra-broad band microstrip band pass filter”, IEEE MTT-S Int. Microw.Symp.Dig., 2000.

\section{AUTHORS}

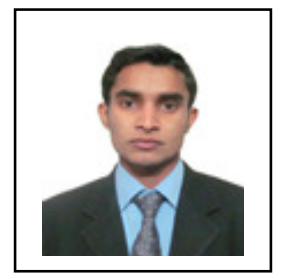

Tasher Ali Sheikh received his B.Tech degree in Electronics and Communication Engineering from Central Institute of Technology (CIT), Kokrajhar, India in 2013. He has undertaken various microstrip filter based projects. His field of interest includes DSP, Microwave Filter design and antenna design for multi-bands applications and Mobile Communication. He enrolled for the Master of Technology in "Mobile Communication and Computing" at National Institute of Technology (NIT), Arunachal Pradesh, India in the month August, 2013.He has published some research paper in Conference and international journals.

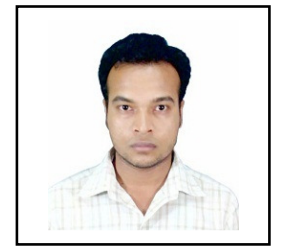

Janmoni Borah received his B.Tech degree in Electronics and Communication Engineering from Central Institute of Technology, Kokrajhar, Indiain 2013. He is currently pursuing M.Tech in Mobile Communication and Computing at National Institute of Technology, Arunachal Pradesh, India. His research interest includes Mobile communication, Microstrip antenna design for multi-band applications, Microstrip filter design and Green computing. He has published some research papers in International journals and conferences.

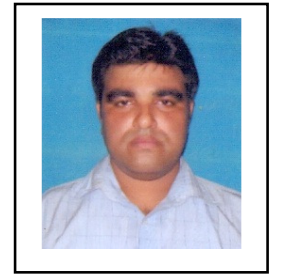

Sahadev Roy is currently working as an Assistant Professor in the Department of Electronics \& Communication Engineering at NIT, Arunachal Pradesh, India. He has more than 10 years' Experience in research and teaching field. He received his B.Tech degree in ECE and M.Tech, in Mechatronics from Bengal Engineering and Science University, Shibpur, India. He is pursuing $\mathrm{PhD}$ in VLSI from NIT, AP. He has published a number of scientific papers in National and International Journals. His research interest includes Robotics, Microwave and VLSI design. 